\title{
Article
}

\section{UNDERSTANDING AND TACKLING GANG VIOLENCE}

\author{
Karen Bullock and Nick Tilley ${ }^{b}$ \\ aDepartment of Sociology, University of Surrey, Guildford, Surrey, UK \\ ${ }^{b}$ Nottingham Trent University, Nottingham, UK \\ Correspondence: Karen Bullock, Department of Sociology, University of Surrey, Guildford, Surrey \\ GU2 7XH, UK. E-mail: k.bullock@surrey.ac.uk
}

\begin{abstract}
Gang-involved shootings comprise a serious problem. A Manchester-based project addressing the issue was tracked and its development is discussed. The initiative moved from a planned focus on the situational determinants of shootings, drawing on the successful Boston Gun Project, to one that focused instead on the social determinants of gang membership. The term "gang" itself is highly ambiguous. Equally there are difficulties in defining and operationalizing the concept of "gang membership" for preventative and enforcement purposes. Practical uncertainties followed for the identification of individuals who belong to gangs or are at risk of becoming members, and hence warrant special project attention. This intrinsic uncertainty paved the way for disagreements between the practitioners in their estimates of the risks of gang involvement faced by individuals, in the selection of young people to focus on within the project, and in levels of concern about the consequences that might follow from negatively stereotyping young people as gang members. It is concluded that it may be more effective and efficient to target specific patterns of violent behaviour rather than gang membership for preventative and enforcement attention.
\end{abstract}

\section{Keywords}

gangs; violence; targeting; prevention; enforcement

Crime Prevention and Community Safety (2008) 10, 36-47. doi:10.1057/palgrave.cpcs.8150057 


\section{Introduction}

A series of tragic and high-profile shootings has raised the issue of gang membership in both the public consciousness and the political arena. With a background of hooded youngsters posing with guns being aired on the television news, there have been renewed calls for attempts either to crack down on the activities of these youngsters or otherwise to prevent them from becoming involved in gang violence.

Shootings - gang related or otherwise - are rare in the UK, but there are good reasons for being concerned about gangs and gang membership. Street gangs are present in most US cities and some - such as the Cripps and the Bloods in Los Angeles - have worldwide notoriety for their violence. American longitudinal studies have consistently shown that "...criminal behaviour committed by gang members is extensive and significantly exceeds that committed by comparatively at-risk but non-gang youth" (Huff, 1998, p 2). Gang members are more likely to commit serious and violent crimes, and they are much more likely to sell drugs and make money from doing so. In regard to guns, gang members have also been found to be much more likely than nongang members to possess powerful weapons (Huff, 1998). Differences in terms of the availability of firearms might make it seem unlikely that street gangs could become as violent as American ones, but there is nevertheless understandable concern about the role of gang members in the commission of violent crime in the UK. Although the picture is mixed and no long-term data on gang behaviour are available in the UK, an overview of existing studies on gangs and gang violence showed that gang members committed more crime than non-gang members, they are more likely to deal drugs, and they are more likely to carry weapons (Marshall et al., 2005).

Developing means of understanding and tackling gang violence would seem to be more important than ever. To date there have been few systematic attempts to understand gang-related violence in the UK and to develop means to prevent it recurring. Thus far, the predominant response to gang-related violence has been to attempt to detect perpetrators and punish them rather than to develop and implement interventions to prevent further incidents occurring. This paper draws on empirical evidence gathered from a multi-agency project based in Manchester that aimed to reduce gang-related violence using problem-oriented principles. Following a research phase the project was staffed by a police project manager, civilian implementation and information managers, and practitioners from the Youth Offending Team, the Housing Department, Probation, Youth Services and Education as well as two ex-gang members who acted as outreach workers. Some 50 interviews with those responsible for designing and setting up the project, for day-to-day implementation of the project and their managers (including senior managers) were conducted at intervals between 2001 and 2003. Project meetings and other key events 
were observed and project records (including minutes of meetings) were examined.

This paper tracks the development and implementation of the Manchester project. The project originally sought to replicate the Boston Gun Project, which focused on tackling the situational determinants of shootings. The Boston Gun Project had shown, counterintuitively, that the root causes of gang membership do not have to be removed to be effective in preventing shootings. The Manchester project mission, however, drifted to one focused on addressing gang membership as a social problem and became concerned with preventing young people from joining gangs or diverting them if they had done so. The paper examines a range of problems that resulted from this mission drift. These included serious differences between practitioners as they struggled to agree on which youngsters were gang involved, use of very variable levels of evidence on gang involvement as young people were selected for project interventions, and unresolved concerns about the risks of labelling and stereotyping young people. Ultimately, it is argued that preventative interventions to tackle shootings would be better focused around aspects of harmful individual or group behaviour rather than on "gangs" and "gang membership" per se.

\section{Reducing gang violence using problem-oriented principles: the Boston and Manchester projects}

The Manchester project was originally conceived along the lines of one of the best known and most successful attempts to reduce violence associated with gangs: the Boston Gun Project. This project was based in Boston, Massachusetts (USA) and was associated with a rapid decline in the number of fatalities caused by the use of guns and knives (Kennedy et al., 1996; Braga et al., 1999). The Boston Gun Project was first and foremost committed to the principles of problem orientation and consequently was a data-driven exercise that sought to develop focused and effective responses to gang-related violence (Decker, 2002). The collection of quantitative and qualitative data to describe gangrelated violence in Boston played a key role in driving this project forward. The project interventions themselves were based primarily on the principle of deterrence. Braga and Kennedy (2002) described how deterrence worked in Boston. Project workers communicated to the gang members which kinds of violent behaviours would not be tolerated by the city of Boston and how they would respond should they engage in these kinds of behaviours. If gang members engaged in these actions, law enforcement practitioners would flood the area conducting a range of enforcement activities such as enacting outstanding arrest warrants, checking bail conditions, etc. This acted as a deterrent in itself, but it also provided incentives for gang members to control one another's behaviour if it risked bringing concerted enforcement attention to all members of the group. At the same time, outreach and other project workers 
would inform gang members that the enforcement was the result of behaviour that was not going to be tolerated. Correspondingly, a range of services would be offered to gang members such as educational provision or diversionary opportunities. A feature of the project was that gang members were effectively selecting attention from law enforcement agencies by their own behaviour (Braga and Kennedy, 2002).

Projects cannot be fully described or fully replicated (Tilley, 1996), but the basic idea was to follow the principles of the Boston project in Manchester. In looking to effect reductions in the levels of shootings through attention to the proximate causes of shootings, the aim was to gather data about the nature of the problem and to formulate responses on the basis of those data. It was not incumbent on the project staff to conduct an initial analysis of gang violence. This was undertaken independently (see Bullock and Tilley, 2002) and involved drawing together a range of data to describe attributes of gang-related violence around which to target preventive efforts. The main data sources included:

1. Police calls for service, recorded crime data, information from the police services day-to-day system for recorded information and intelligence on people, crimes and incidents.

2. Interviews with gang members in prison, police officers and other informed practitioners.

Attempts were also made to elicit data from non-police agencies that may have had additional information relevant to serious youth violence, including various local authority departments, the probation service, schools and hospitals. In the event, little systematic data for statistical analysis were gleaned from these sources, although they furnished some qualitative material.

\section{Findings: Manchester gangs and gang-related shootings}

Bullock and Tilley (2002) identified four main gangs loosely based in the South Manchester area. The gangs comprised a mix of similar-age local friendship groups, blood relatives and recruits. Gang members engaged in a wide range of criminal behaviour that included drug-related offences, but only as one element of a patchwork of violent and non-violent crime. Alliances were sometimes formed between South Manchester gangs, but conflict was endemic and easily triggered. Gang members carried firearms for different reasons that were partly protective, partly symbolic and partly instrumental for the commission of violent crime. Bullock and Tilley (2002) found that violence in general, gun violence in particular and fatal shootings most specifically were concentrated in very specific small areas of South Manchester. The victims and the suspected perpetrators of gun violence tended to have similar attributes and were mainly young, black or mixed race males, who had extensive criminal records. The 
victims of shootings in South Manchester were generally known to have been involved in gangs.

\section{Drift: the development and implementation of the Manchester project}

With the replication of the Boston project in mind, the original primary aim was to deter violence through highly publicized multi-agency crackdowns. Practitioners were to engage directly with gang members to transmit consistent messages about targeted crackdowns and to offer diversionary services. Targeted multi-agency enforcement activities would be executed in specific areas where certain forms of violent behaviour persisted.

The inter-agency team of seconded practitioners came to understand the project very differently from the principles set out above. In practice it was understood as follows: enforcement activities would be targeted only on individuals who had been offered help and support to remain clear from offending and gangs and had either refused it or continued to offend. Crackdown was seen as a threat for non-cooperative individuals, rather than a threat for groups if a member of that group behaved in specific pre-determined ways. As this quote from a housing practitioner in February 2003 demonstrates “... the carrot and stick. You work with us we work with you. You don't work with us, these things will happen to you. That message needs to be made crystal clear". One of the Youth Offending Team practitioners stated in June 2002 that "...we have to chat to people but if they don't play ball with us, enforcement will follow."

More generally the project mission drifted from its roots in the Boston Gun Project and tackling situational determinants of shootings towards tackling the social determinants of gang membership. The project team expanded the project scope during the early stages of its development to better suit their views about the nature of the problem and appropriate ways of tackling it. One of the civilian project team members stated in August 2001, for example, "... we have to tackle gang culture to reduce firearms crime because the two are linked." And later in the same interview he said that "...initially the project was very focused on firearms but we realised that the problem was the gangs. If the gangs are still there the problem will come back." This shift towards a long-term preventative programme was cemented during the early months of its delivery. Many of the practitioners employed to work on the project saw their roles primarily in terms of preventing and diverting youngsters from engaging in gang-related activities rather than enforcing the criminal or civil law. The project social worker stated in June 2002, for example, that "...I am specifically involved in looking at holistic need and in linking in with other agencies to take on aspects of care when necessary." An education officer in December 2001 commented, “...it's [the project's] intention to bring bumanity 
back to the kids. This means being about to support parents in parenting their children." Because of their preferences for supportive and preventative interventions, little enforcement activity - however conceived - against gang members was conducted in the name of the project.

The thrust of the project then became that of identifying gang members or those at risk of becoming involved and developing preventative and diversionary interventions. It is not for the moment being argued that this shift from the situational determinants of shootings to the social determinants of gang membership was necessarily irrational or misguided, just that it was very different from what had been agreed and planned earlier. However, this shift created certain difficulties that influenced the delivery of the project. Seeking to operationalize notions of gangs and gang membership for preventative purposes is hard and it follows that it is harder still to determine who might be at risk of joining a gang but has not yet done so. Determining those individuals who were in gangs or who were at risk of joining gangs - hence suitable for preventative interventions - proved problematic in a practical sense in a number of ways.

\section{Determining gang membership for preventative purposes}

\section{Factors indicating elevated risk of gang membership}

The identification of gang members and those at risk of joining a gang was left to the judgement of the practitioner team. This approach to identifying risk is quite common. For example, in their overview of 12 studies of gang-related violence, Marshall et al. (2005) noted that gang members were identified in different ways but usually either through self-reporting or by practitioners. How a specific individual comes to be identified as a gang member by practitioners, however, is less clear and is complicated by variations in gang activity over space and over time (Marshall et al., 2005). A similar point was made by Braga and Kennedy (2002), who noted that gangs in Boston were defined by the authorities in certain ways that differ from those used in other cities.

Observations of project meetings and examination of records uncovered a wide range of factors that practitioners considered potentially to indicate risk of gang association:

- The offending history of the individual, his family and peers.

- Involvement in drug dealing.

- Association with (either known or suspected) firearms.

- Association with prominent gang members.

- A sibling, son or daughter of a gang member.

- Regular visits to or residence within a prominent gang area.

- Victimization by gangs.

- Ownership of possessions beyond means. 
- Reckless or unpredictable behaviour.

- Mental health problems, low self-esteem, drug problems or easily led.

- Being in local authority care, having abusive or violent parents, parental neglect.

- Homelessness or residence in supported accommodation.

- Truancy or exclusion from school.

By the summer of 2001, the project team had identified some 850 individuals deemed to be gang members, associates of gang members or at risk of becoming gang members in South Manchester. It was not going to be possible to work with all these individuals. As one of the senior practitioners stated in an interview in March 2003, “... my concern is that you have a thousand kids, under the age of 25 , involved in gangs. To have a team, of less than a dozen people working with them is just scratching the surface." This problem was exacerbated because the project started to take referrals.

The project management had instructed the practitioners proactively to identify and develop interventions for only 85 individuals (at least to begin with). The project received referrals early on as awareness of the initiative increased among practitioners in Manchester. A manager from the social services remarked in June 2002 that "...cases have not all been driven from the Wednesday meeting because people at work are realising [the project] is around, they are getting in touch and asking for help." There were other cases of young people effectively referring themselves to the scheme. For example, at a meeting observed on 16 January 2002, there was a discussion about a young man called "Andy". Andy appeared to have strong associations with the South Manchester gangs but had become scared of the violence and wanted to leave; he had apparently asked a police officer whether there was help available. The project decided that in these circumstances it would not make sense to refuse to help support this young man in his attempt to leave the gangs. By the end of March 2003, 172 individuals (twice the originally specified number) had been assessed for inclusion into the project and the potential workload was spiralling. One practitioner noted in 2002 that “...there is no system of referral yet the project is taking referrals. If it continues in the same way the workers are going to be swamped with requests. As awareness is raised there will be more demand."

\section{Diverging views of risk and variable indicators of gang involvement}

In the absence of a clear understanding of the factors that lead young people to join gangs, practitioners struggled to agree on who was at elevated risk. This led to disagreement in practice between practitioners on who should be included for project interventions. For example, at a practitioners' meeting in October 2001, a discussion was held about one young man, "Martin", who 
had been identified as at risk. Martin's older brother, a well-known gang member, was in prison at the time but was due for release, and there was concern that on his release his influence might turn Martin towards the gangs. There was evidence that Martin was disruptive at school, but he had no criminal record and was not known to the police service. The outreach workers were adamant that Martin should not have been selected for preventative interventions because, they felt, he was very marginal to the gangs and his level of risk was no greater or less than anyone else who lived in the area. However, others argued that he should be included and eventually Martin was included for interventions on the basis of the potential disruptive influence of his brother.

In interviews, the practitioners themselves expressed concerns on whether the project was working with the right people. A member of the housing department stated in January 2002 that “...there is some question about the names on the target list and whether they should be there or not, especially the girls." The outreach workers (who had once been gang members themselves) were particularly concerned about whether the right people were being selected for interventions from the project. This related especially to whether or not they were sufficiently involved in gangs to merit intervention as this outreach worker suggested in November 2001: "The focus has been far too much on those on the periphery of the gangs but anyone who lives in [South Manchester] could be considered to be on the periphery of the gangs ... at the moment there are far too many people on the periphery of the gangs for this to be a sensible way of prioritizing."

\section{Labelling and stigma}

As well as impacting the capacity of the project and creating disagreements among practitioners, the lack of clarity about how to target individuals for interventions was considered by some of the practitioners potentially to have negative implications for the young people themselves. Some practitioners felt that it was important to target only those individuals who were known to be gang members or were at very serious risk of being involved. Their experience highlighted the stigma that could be associated with gang membership and possible resistance from parents who rejected that label being attached to their children. A Youth Offending Team practitioner stated in June 2002 that "...parents take a step backwards when you mention gangs. Parents deny and resist ... because of stigma. There is greater stigma attached to gang membership than crime."

There were also suggestions that the negative connotations associated with being labelled as a gang member could cause difficulties for young people when trying to access services from agencies:

That's where the project is detrimental. If you start mentioning anything to do with gangs then they [the schools] definitely won't want them back. Unless 
they ask me specifics, I just say that they are at risk of being involved [in gangs] and just working around those issues and providing support. Youth Offending Team practitioner, February 2003

These quotes resonate with points made by Marshall et al. (2005), who argued that practitioner reports of gang membership may be misleading and that the young people themselves may well not use the term gang to describe those with whom they associate. They argued that “...the word gang conjures up stereotypical images that are misleading at best and destructive at worst. Certainly not all groups of young people are violent, gun carrying drug dealers" (Marshall et al., 2005, p 7). They went on to refer to an unpublished youth justice board report that suggested that practitioners feel that labelling youngsters as gang members may, on the one hand, criminalize behaviour when the term gang is "permissively applied". On the other hand, the term may provide groups with a "kudos" or status that is not justified and which reinforces the problem (Marshall et al., 2005, pp 7-8). There are thus risks of labelling gang members as such: young people (or their families) may resist that label; it may promote negative responses from agencies when trying to access support for them; it might "criminalize" forms of behaviour or at least define them as problematic when this is not justified; and finally, it might exacerbate a problem through giving it a status it does not deserve.

\section{Discussion and conclusion}

This paper describes an attempt to apply problem-oriented principles to serious gang-related violence in Manchester, drawing on the successful Boston Gun Project. The Manchester project never applied the multi-agency crackdowns that proved to be such a successful deterrent to gang-related violence in Boston. The original logic of the Manchester project was modified in the early days of its delivery. Its primary concern shifted from tackling the situational determinants of shootings to the social determinants of gang membership. This was the result of the preferences of the practitioner team who, in contrast to their Boston counterparts, perceived the problems of shootings in terms of gang membership and were first and foremost concerned with altering the social conditions that they believed caused the gangs to arise and persist. This difference in view and the project change in focus firmly removed its anchor in the Boston initiative.

As well as representing a shift in the original project rationale, the move to tackling the social causes of gang membership created a range of problems that shaped the ways in which the project was delivered. In particular, this study found that using "gang membership" as a means of orientating enforcement and preventative action is highly problematic. As has tended to be the case in other projects tackling gang-related violence, the task of determining which 
young people were gang members or at risk of becoming gang members in South Manchester was left to the judgement of the practitioner team. In the absence of a clear understanding of what constitutes elevated risk of gang involvement, the practitioner team assessed risk on the basis of diverse indicators. This resulted in a number of problems:

- Very many young people were swept into the project radar, resulting in a broad and difficult-to-manage project. It was not going to be possible to work with all those young people who had been identified as potentially at risk.

- In the absence of criteria for assessing levels of risk, youngsters were included for project interventions on the basis of very variable indicators of gang involvement.

- There was disagreement between the practitioners on who should be included in the project.

- There was stigma attached to the label of gang members, which parents and youngsters resisted.

- The label "gang member" was believed potentially to have negative consequences for young people in that it might deter some agencies from working with them and might also bestow an identity, which those individuals then think they have to live up to.

The ambiguity surrounding the term "gang" and the problems that have been experienced defining it led Marshall et al. (2005) to suggest that it should be abandoned for the purposes of operational activity and that aspects of gang members' behaviour should be focused on instead (e.g., their prolific offending). The Manchester experience certainly suggests that orientating operational activity around reducing the propensity to join gangs is problematic. The notion of gangs as a social problem creates practical difficulties because it lacks a discrete focus around which interventions and activities can be developed and targeted. A discrete problem focus is essential if police officers and partners are to understand why a problem recurs and develop responses to it (Goldstein, 1990). Broadly defined problems lead to poorly focused responses that are too ambitious (Clarke, 1998). Scott (2000) similarly argued that characterizing problems with broad labels such as "drugs", "violence", "disorder", "neighbourhood decline" or "juveniles" without specifying specific actions and forms of behaviour results in simplistic analysis and responses that are likely to be inadequate (Scott, 2000, p 49). Eck (2001) argued that at the very least problems should be specified in terms of the actions of individuals rather than in terms of their status, the harm that a problem is causing, evidence of the repetitive nature of the problem, and an assessment of how the problem is seen through the eyes of the public.

It is contended that orientating preventative or enforcement actions around the problematic behaviours that gang members exhibit - such as shootings or 
other specific forms of violence - may be more effective and more efficient than orientating that activity around gang membership or a gang per se. The Boston Gun Project - perhaps the most successful attempt to reduce gang-related violence that has been seen yet - relied on problematic behaviours in defining its deterrent strategy. That is to say, it did not use a young person's gang membership or risk of gang membership as the trigger for deterrent and preventative action. Instead it used the enactment of specific violent behaviours to drive the application of the multi-agency crackdowns. In contrast to how the project was conceived, developed and delivered in Manchester, it is suggested that the focus on specific, problematic behaviours in Boston (rather than their status as gang members per se) had the following benefits:

1. Interventions were focused around certain explicit behaviours that were clear to both perpetrators of violence and practitioners seeking to tackle it.

2. The problematic decisions about what features of a young person's background or lifestyle make them vulnerable to gang membership were not necessary. Interventions were thus not reliant on the preconceived views of practitioners (which might turn out to be mistaken) regarding who was a gang member or at risk of becoming one.

3. A focus on behaviour rather than status may have been more meaningful to the youngsters themselves who may not have perceived their "gang membership" to be anything more than hanging around with their friends.

4. Through focusing on certain kinds of behaviour, the status of an individual was downplayed and aspects of their behaviour emphasized. It would be harder for parents and youngsters to resist activity from agencies as unfair or unnecessary when they are focused around identifiable, specific and dangerous behaviours.

5. It would seem that an initiative to tackle specific forms of violence would make more efficient use of resources and result in a more manageable project than one targeting the broader concept of gang membership.

\section{References}

Braga, A. and Kennedy, D. (2002). Reducing Gang Violence in Boston. In Reed, W. and Decker, S. (eds) Responding to Gangs: Evaluation and Research. Washington: National Institute of Justice.

Braga, A., Kennedy, D. and Piehl, A. (1999). Problem-Oriented Policing and Youth Violence: An Evaluation of the Boston Gun Project. Washington, DC: Unpublished Report to the National Institute of Justice.

Bullock, K. and Tilley, N. (2002). Shootings, Gangs and Violent Incidents in Manchester: Developing a crime reduction strategy. Crime Reduction Research Series Paper 13. London: Home office. 
Clarke, R. (1998). Defining Police Strategies. In Shelley, T.O. and Grant, A.C. (eds) Problem-oriented Policing: Crime-Specific Problems, Critical Issues and Making POP Work. Washington, DC: Police Executive Research Forum.

Decker, S. (2002). A Decade of Gang Research: Findings of the National Institute of Justice Gang Portfolio. In Reed, W. and Decker, S. (eds) Responding to Gangs: Evaluation and Research. Washington: National Institute of Justice.

Eck, J. (2001). Problem-oriented Policing and its Problems. The Means Over Ends Syndrome Strikes Back and the Return of the Problem Solver (unpublished draft).

Goldstein, H. (1990). Problem-Oriented Policing. New York: McGraw Hill.

Huff, C. (1998). Comparing the Criminal Behavior of Youth Gangs and At-Risk Youths. Washington: National Institute of Justice.

Kennedy, D., Piehl, A. and Braga, A. (1996). Youth Violence in Boston: Gun Markets, Serious Youth Violence, and a Use-reduction Strategy. Law and Contemporary Problems. Vol. 59, No. 1, pp 147-196.

Marshall, B., Webb, B. and Tilley, N. (2005). Rationalisation of Current Research on Guns, Gangs and Other Weapons: Phase One. London: UCL.

Scott, M. (2000). Problem-Oriented Policing: Reflections on the First 20 Years. Washington, DC: US Department of Justice, Office of Community Oriented Policing Services.

Tilley, N. (1996). Demonstration, Exemplification, Duplication and Replication in Evaluation Research. Evaluation. Vol. 2, No. 1, pp 35-50. 